\title{
Experiencing Language: What's Missing in Linguistic Pragmatism?
}

\section{Mark Johnson}

\section{OpenEdition}

\section{Journals}

Electronic version

URL: http://journals.openedition.org/ejpap/284

DOI: $10.4000 /$ ejpap.284

ISSN: 2036-4091

\section{Publisher}

Associazione Pragma

Electronic reference

Mark Johnson, «Experiencing Language: What's Missing in Linguistic Pragmatism? », European Journal of Pragmatism and American Philosophy [Online], VI-2 | 2014, Online since 24 December 2014, connection on 21 April 2019. URL : http://journals.openedition.org/ejpap/284 ; DOI : 10.4000/ ejpap.284

\section{(c) (7) $\ominus$}

Author retains copyright and grants the European Journal of Pragmatism and American Philosophy right of first publication with the work simultaneously licensed under a Creative Commons AttributionNonCommercial-NoDerivatives 4.0 International License. 


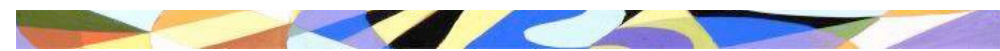

EUROPEAN JOURNAL OF PRAGMATISM AND AMERICAN PHILOSOPHY

COPYRIGHT C 2009 ASSOCIAZIONE PRAGMA

Mark Johnson*

\section{Experiencing Language: What's Missing in Linguistic Pragmatism?}

Abstract: The emergence of linguistic pragmatism has given rise to a lively debate over whether philosophy should focus on language or experience. But the experience vs. language dichotomy is just another type of dualism of the sort that pragmatists ought to be wary of. We need to appreciate that, insofar as pragmatism aspires to elucidate and transform our meaningful experience, it must recognize that meaning goes deeper than language. What linguistic pragmatists hope to do with language cannot be done without meaning resources that are not themselves linguistic. Meaning, understanding, thinking, and valuing all have to be enacted as embodied processes. Moreover, no use or analysis of language is possible without an experience of meaning, and so we can never avoid experience in our philosophical undertakings, even granting that there is no perspective-free take on what some thing or event means.

Pragmatism is a growing, vital philosophical tradition, and one of its recent growth spurts has been the emergence of what has come to be known as "linguistic pragmatism". This new brand of pragmatism is "linguistic" because it takes language to be the most distinctive capacity marking off humans from other sentient species, and it argues that there is nothing beyond language that might ultimately ground any particular truth claim emerging from any discipline or practice. Linguistic pragmatism is what you get when you start with analytic philosophy's founding assumption that language is our access to any meaning we are capable of experiencing and then supplement this with the pragmatist insight that meaning is a mode of action tied to values and forms of communicative interaction. If it is our language that supplies us with all the conceptual distinctions we can make, then one might be led to conclude, as linguistic pragmatists do, that philosophy's focus should be on the conditions that make linguistic assertion and performance possible as a communal activity.

This assumption about the primacy of language has generated a lively debate within pragmatist circles concerning the insistence in earlier "classical" pragmatist thinkers like James and Dewey that philosophy ought to emerge from, and return to, experience, and not just language. The controversy about whether experience or language is the alpha and omega of philosophical reflection has also coincidentally turned into a contest over who can properly claim to be a pragmatist philosopher, as in "Will the real pragmatist please stand up?".

Now, to state the obvious, any strong contrast between experience and language is just one more big dichotomy! But aren't pragmatists supposedly known for eschewing dualisms that function as rigid hypostatizations and thereby fail to capture the continuity, richness, and complexity of experience? How ironic, then, that selfproclaimed pragmatists would find themselves defending their preferred side of a basic experience/language dichotomy. Yet, here I am, writing for this present volume

* University of Oregon [markj@uoregon.edu] 
precisely on the subject of whether experience or language ought to be viewed as our primary philosophical focus.

I will argue that there is no such thing as "language" in itself - no language without our experience of language, and no language experience without an enactment of meaning that involves more than just linguistic structures. Consequently, we cannot pretend to escape the depths of experience by focusing only on language and linguistic practices of validation and justification, for there are no such practices that are not themselves experiences embedded within a context of perceiving, meaningmaking, appraisal, and acting that is not itself all or only a matter of language. It is a mistake to set language over against experience, for all linguistic practices are forms of experience. In short, I will argue that there are three things missing in linguistic pragmatism: (1) a nuanced account of language (as it is actually experienced), (2) an adequate understanding of meaning (including its non-linguistic dimensions), and (3) a sufficiently rich notion of experience (that goes beyond linguistic events). It turns out that this issue is not just a minor in-house skirmish over who gets to be the "true" pragmatist. Rather, it is a matter of what philosophy ought to be and to do, if it hopes to make any significant positive difference in our lives.

\section{Linguistic Pragmatism}

One source of the language vs. experience debate is Richard Rorty's contrast between the "good Dewey" and the "bad Dewey" (Rorty 1982). Rorty's good Dewey is the anti-foundationalist, anti-dualistic philosopher who unmasked our inveterate but fruitless desire for certain and timeless truths, with their correlative modes of knowing. This is the Dewey who showed us all the dead-ends and confusions we are led to when we engage in rigidly dichotomous thinking that assumes that our dualisms capture essential structures of some mind-independent Reality that supposedly grounds all our claims to knowledge and truth. The bad Dewey, from Rorty's perspective, is the person who, having demolished foundationalist epistemology and jettisoned dualistic metaphysical thinking, lost the courage of his convictions when he claimed that we could ground our understanding and knowledge in something called "experience", which could be explored within an "empirical metaphysics" of the "generic traits of existence". Rorty's bad Dewey, in other words, thinks we can still have a nonfoundationalist, "empirical" metaphysics of experience. Rorty regards the term "empirical metaphysics" as an oxymoron, because he thinks that metaphysics is an intrinsically foundational enterprise, and, as such, ought to be abandoned, in the face of numerous anti-foundationalist arguments.

What came to be known as Rorty's (and, later, Putnam's) "Neo-pragmatism" paved the way for a number of subsequent influential philosophers who might be called either "new pragmatists" or "linguistic pragmatists". This new linguistic orientation is well represented in books such as Cheryl Misak's New Pragmatists (2007), Alan Malachowski's The New Pragmatism (2010), Robert Brandom's Perspectives on Pragmatism (2011), and Robert Talisse and Scott Aiken's The Pragmatism Reader (2011). The basic idea of linguistic pragmatism, which I will examine in more 
detail below, is that (1) the human mind is characterized by its capacity for reasoned judgments concerning various assertions and knowledge claims, (2) this entire process is dependent on language (via conceptual and propositional structures that are linguaform), and (3) our standards of assertion and our claims to reasonableness are constrained by conditions of social interaction within communities of inquirers. In short, the mind's distinctive capacity for certain kinds of cognitive operations depends on our linguistic capacities and the communities of inquirers within which we find ourselves. Linguistic pragmatists hold that one cannot pretend to justify knowledge or truth claims by reference to some allegedly non- or pre-linguistic "experience" that supposedly provides the ultimate constraints on what counts as knowledge. Experience, on this view, is either already a linguistic construct, or else it has no standing in selecting out which concepts, truth claims, and modes of knowing are sanctioned by communities of inquirers. Alan Malachowski sums up this suspicion of "experience" as follows: "New Pragmatism has not bound itself by the sorts of commitments that were always going to hold classic pragmatism back. Of these, empiricism, with the accent on experience, is the principal factor. New Pragmatists are able to discard much philosophical baggage by shifting its focus to language" (Malachowski 2010: 31).

In Consequences of Pragmatism (1982), Rorty praises Dewey for replacing the notion of language as a medium for representing an independent reality, with the notion of language as tool for coordinating human behaviors. Rorty cautions us not to regard this tool analogy as implying that language is somehow separable from its users and their world:

But we must be careful not to phrase this analogy so as to suggest that one can separate the tool, Language, from its users and inquire as to its "adequacy" to achieve our purposes. The latter suggestion presupposes that there is some way of breaking out of language in order to compare it with something else. But there is no way to think about either the world or our purposes except by using our language. One can use language to criticize and enlarge itself, as one can exercise one's body to develop and strengthen and enlarge it, but one cannot see language-as-a-whole in relation to something else to which it applies, or for which it is a means to an end. (Rorty 1982: xix)

The key claim here is that, when it comes to matters of meaning, understanding, and knowing, there is nothing beneath or beyond language against which our linguistic articulations might be measured or evaluated. Rorty doesn't make the ridiculous claim that there is nothing beyond language, but only that our practices of communicating, assessing truth-claims, and coordinating action are linguistically structured, through and through. In short, "attempts to get back behind language to something which 'grounds' it, or which it 'expresses', or to which it might hope to be 'adequate', have not worked. The ubiquity of language is a matter of language moving into the vacancies left by the failure of all the various candidates for the position of 'natural starting-points' of thought, starting-points which are prior to and independent of the way some culture speaks or spoke" (Rorty 1982: xx).

More recently, Robert Brandom has expanded and articulated this linguistic 
perspective with a vengeance. In a series of impressive books, Brandom has given a very insightful and interesting account of the historical development of various pragmatist claims and commitments. He does justice to the pragmatist emphasis on activities of meaning-making as forms of engaged practice. However, after having surveyed a range of classic pragmatist themes, Brandom expresses his own preference for one specific linguistic version of what he calls fundamental pragmatism, by which he means "the idea that one should understand knowing that as a kind of knowing how (to put it in Rylean terms). That is, believing that things are thus-and-so is to be understood in terms of practical abilities to do something" (Brandom 2011: 9). Brandom's way of phrasing the pragmatist reconceptualization of knowing is to say that what he calls "discursive" intentionality (which many have regarded as the distinguishing human capacity) is actually a form of "practical" activity:

Practical intentionality is the kind of attunement to their environment that intelligent non-linguistic animals display - the way they can practically take or treat things as prey or predator, food, sexual partner or rival and cope with them accordingly. Discursive intentionality is using concepts in judgment and intentional action, being able explicitly to take things to be thus-and-so, to entertain and evaluate propositions, formulate rules and principles. The fundamental pragmatist aspiration is to be able to exhibit discursive intentionality as a distinctive kind of practical intentionality." (Brandom 2011: 10)

So far, so good, you might say, insofar as pragmatism sees thinking and communicating as types of practice and sees that our highest forms of discursive reasoning are grounded in our practical engagements with others in our shared social communities. Notice, however, that we have already slipped almost imperceptibly into an extremely narrow conception of experience that limits it to matters of belief, judgment, appraisal, and reason-giving (albeit, conceived as modes of action). The experience that Brandom's pragmatist philosopher is interested in consists of experiences of assertion, reasoning, justification, and appraisal. This bias is evident in Brandom's description of experience as primarily about rational inquiry and justification. As he says, 'the pragmatists' conception of experience is recognizably a naturalized version of the rational process of critically winnowing and actively extrapolating commitments" (Brandom 2011: 8).

It should not be surprising, therefore, when Brandom embraces the idea that analysis of language is the key to explaining conceptual structure. He describes the "linguistic turn" as "putting language at the center of philosophical concerns and understanding philosophical problems to begin with in terms of the language one uses in formulating them" (Brandom 2011: 22). He espouses what he calls "lingualism" - "commitment to understanding conceptual capacities (discursiveness in general) in terms of linguistic capacities" (Brandom 2011: 22). What we have here is an analytic philosophical perspective enriched with a pragmatist attention to action. Note, however, that the "actions" are principally linguistic acts.

Now, one might not find anything amiss in these statements, as far as they go, insofar as language gives us one way to explore aspects of our conceptualization and reasoning. Indeed, this is one of the key insights and motivations of analytic 
philosophy, which has taught us much about the nature of our conceptual systems. The problems arise, however, from the exclusive focus on linguistic practices, which leads the linguistic pragmatist to ignore the importance of vast expanses of human meaning-making and experience. Language is not the only window into our concepts, for there are many other forms of symbolic interaction that reveal our conceptual patterns and modes of inference, including spontaneous gestures, music, painting, dance, architecture, and ritual practices. Moreover, it does not necessarily follow from the importance of language as a lens for studying concepts that all our experience is linguistically structured and demarcated (a point to which I will return later).

Let us summarize the version of linguistic pragmatism operating here. Thinking is a doing, and it is a doing through language, according to shared norms for asserting and justifying claims within a particular community. "Experience" is understood predominately as forms of assertion and reason-giving according to norms of communal interaction. As Brandom says, "pragmatists who have made the linguistic turn take it that the most important feature of the natural history of creatures like us is that we have come into language: come to engage in distinctively linguistic abilities" (Brandom 2011: 26).

David Macarthur and Huw Price have espoused a similar lingualism when they write that "pragmatism begins with questions about the functions and genealogy of certain linguistic items - emphasizing that unless we stipulate otherwise, we're always assuming that these items may be mental, as well as strictly linguistic (in the ordinary sense)" (Macarthur and Price 2007: 95). A critic of this strong lingualism might be inclined to say that, although pragmatism might possibly begin with analysis of linguistic expressions, it does not follow that its inquiries must end with language. In other words, the critic would argue that there is more to experience than what is presentable through language. However, Macarthur and Price are pretty clear about the exclusively linguistic focus they are proposing, for they insist that "a pragmatist about causation asks not about the role of causation itself in human life, but about the role and genealogy of the notion, terms, or concept 'causation"' (Macarthur and Price 2007: 94). They go on to diagram their view as Pragmatism=Linguistic Priority without Representationalism (Macarthur and Price 2007: 97).

There are other versions of linguistic pragmatism, but I shall use Brandom's highly detailed and well-argued version as my stalking horse. I want to ask, first, how and why did we get to a place where "experience" gets cashed out primarily as "linguistic experience"? I am reminded of the old, tired joke about the drunk who is stumbling around looking for his car keys under a streetlight. A passerby inquires why he is searching there, when the drunk's car is parked down the street. The intoxicated fellow replies that the light is better here, under the streetlight. Well, maybe that's the way it is with language and experience, too - language is alleged to be the light by which we understand anything, and so we conclude that what is discovered through language is all there is, or, at least, all that matters. In other words, in the light of language, all experience seems to be linguistic, once it is assumed that we can only mark distinctions and see the patterns that our language provides us. And this view is reinforced by the fact that we can only talk about experience using language. 


\section{Meaning Beyond Language}

The experience $v s$. language debate has come to take a predictable form. The experientialists observe that experience is not just a product of linguistic structures, concepts, and knowledge, but instead extends far beyond our ways of knowing and our linguistic tools for identifying and analyzing our conceptual structures. The lingualist responds by observing that only language, which allows us to mark off relevant meaning structures, gives us access to our conceptual systems. Therefore, our capacity to think in the ways we do is contingent on our linguistic abilities, and the lingualist goes on to remind us that language is not a medium for expressing some non-linguistic reality (i.e., experience), but is a way of coordinating human activities through speech acts.

I cast my fate with the experientialists, not to set language over against experience, but to see language as a form of experience, while at the same time remaining suspicious of any strong experience/language dichotomy. While the linguistic pragmatists do capture important dimensions of Dewey's view, they only get part of the story of experience, meaning, and thought. I will argue that their conception of language is too shallow, insofar as it focuses only on linguistic elements (words, sentences, speech acts). I take issue with the idea that whatever meaning there is must be expressible, in principle at least, by some language (as lingualists understand it). In other words, I challenge the idea that all thought is linguaform - linguistically expressible as a set of concepts, propositions, and their relations. My view is that, although our capacity for linguistic expression may well be a distinctly human ability that allows us to engage in all sorts of marvelous abstract thinking, it does not follow that "whatever can be meant can be said" (Searle 1969). Therefore, I need to show at least two things: (1) that if language is limited only to linguistic signs (words, sentences, etc.), then there are meaning-making processes besides linguistic ones, and (2) there is no language without our experience of language, so that any alleged contrast of "language" versus "experience" can really only amount to a distinction between linguistic experience and other kinds of experience.

I begin my argument, then, with how our resources of meaning-making far exceed linguistics resources based only on words and their combinations. Let's start with a simple example of how meaningful experience exceeds language. When I was in high school, after a football or basketball game, I used to bring my girlfriend to my house, and, when nobody was home, we would dance together. I would put a Nat King Cole record album on my father's turntable, turn out most of the lights, and we would move slowly around the room, pressed steamily together under the sway of Cole's rich, deep, mellow voice. Now, there was plenty of highly charged meaningful action going on there, and there were several norms in play, but virtually none of them had anything to do with language proper. The ways we held each other, where my hand rested on her back, how she let her head rest on my shoulder, the fragrance of her hair, how we moved around the room as the wooden floor creaked under our feet, how we hesitated briefly each time one song ended and we waited 
awkwardly for the next track to begin, hearing only the scratching and popping sound of the well-played record. It was all meaningful, and there were shared intentions and interests and values permeating our experience, and most of that was not dependent on language.

This issue here is whether all meaning is linguistic (i.e., dependent on language), or whether linguistic meaning is rooted in a vast pre-linguistic play of meaning structures. In my own work I have devoted a good deal of effort to exploring these non-linguistic aspects of meaning (Johnson 2007), but I know all too well that most contemporary analytic philosophers emphatically reject this view. The lingualist will insist that language gives us our only access to the depths of meaning, so that, whatever cannot be expressed linguistically, cannot properly count as meaning. They demand that the experientialist tell them what the dimensions of meaning are within a particular situation, and they then play their trump card by noting that the experientialist inescapably resorts to language in order to try to describe the hidden depths of meaning.

There are two ways to respond to the linguistic pragmatist's exclusive focus on the linguistic. One can argue either that there is far more to meaning than can be captured in written and spoken language, or, alternatively, one could argue that "language" includes any forms of symbolic interaction, and so it extends far beyond the realm of words and sentences. Both strategies are appropriate, so let us consider each in turn.

First, let us address the idea of meaning beyond language. Is what I've just described in the dancing scenario really meaning? Well, it all comes down to what one means by meaning, of course. It is difficult to avoid the sneaking suspicion that there is no "fact of the matter" about what meaning is, so one is left stipulating a definition and then using that to construct arguments about the role of language in meaning-making. The lingualists stipulate that there is no meaning that is not linguistic, whereas the experientialists stipulate that meaning is about the relation of one event to another $-\mathrm{a}$ relation that can obtain prior to, and without, linguistic signs.

I have elsewhere (Johnson 2007) argued that the meaning of any thing, sign, action, or event is the experiences it in some way points to, enacts for us, or leads us to consider. Those discriminated experiences can be past, present, or future (i.e., possibilities for actions or events that might occur). For instance, our experience of a blue, cloudless sky can mean many things, as it calls up past experiences, our present situation, or projected future experiences that might occur subsequently. It can mean that it is not raining (present experience) and will not soon rain (future experience). It will therefore mean that I don't need to take my rain jacket with me when I go fishing. It might mean that fishing will slow down, because the fish will hunker down in deep waters to avoid the sunlight. It might mean that I might want to put on an extra layer of sunblock for the next few hours. Or, it might recall for me that last sunny day like this when I fished on a particular Cascade high lake and caught the biggest rainbow trout of my life (past event).

The lingualist will object that I'm misusing the notion of meaning, because meanings must be shared and public, and this publicity and communicability are made possible only by a common language, in which terms can stand for certain objects and 
events. They insist that the kinds of experience I'm referring to do not have meaning in the proper sense of that term, which must be restricted, they say, to something only sentences (or parts of sentences) can have.

My response to this challenge is to argue that there is meaning wherever and whenever some thing or event can stand as a sign of some experience. Natural languages are perhaps our most remarkable tools for establishing and stabilizing these sign relations, but they are not the sole means for shared meaning. Objects, qualities, and events can serve the signification function by employing various perceptual, motor, and affective processes, some of which are not language dependent.

Dewey gives mixed signals on the issue of whether we need language to have meaning. Sometimes he appears to suggest that we only experience genuine meaning where there is language, consisting of linguistic signs standing in various relations to one another and capable of indicating various experiences. In Chapter 5 of Experience and Nature he argues that we achieve "mind" when we learn to interact and communicate with others in a communal way through language, and he repeatedly asserts that it is language that makes shared meaning possible.

However, in that same book, Dewey offers examples of pre-reflective dimensions of experience that have meaning insofar as they recall experiences past, direct us to future consequences, guide our expectations, and influence our cooperative interactions. As such, these dimensions seem to be primary bearers of meaning:

This state of things in which qualitatively different feelings are not just had but are significant of objective differences, is mind. Feelings are no longer just felt. They have and they make sense; record and prophesy.

That is to say, difference in qualities (feelings) of acts when employed as indications of acts performed and to be performed and as signs of their consequences, mean something. And they mean it directly; the meaning is had as their own character [...]. Without language, the qualities or organic action that are feelings are pains, pleasures, odors, colors, noises, tones, only potentially and proleptically. With language, they are discriminated and identified [...]. When named, they enable identification and discrimination of things to take place as means in a further course of inclusive interaction. (Dewey 1925: 198)

Here is Dewey giving something to the experientialists and something to the lingualists, both at the same time. As the experientialist would have it, Dewey recognizes that whenever we can discriminate qualitative differences as a way of indicating possibilities for experience, we can then go beyond merely feeling a quality and grasp its sense and meaning for us. There are ways of marking differences in qualitative experience that are not strictly language dependent. On the other hand, Dewey gives to the lingualists the idea that language is our primary and most expansive means for marking differences, for understanding things, for constructing meaning.

The key point here is that it is not just linguistic signs that can have meaning. There are many diverse types of things and events that can function as vehicles of possible consequences in experience. 
The qualities of situations in which organisms and surrounding conditions interact, when discriminated, make sense. Sense is distinct from feeling, for it has a recognized reference; it is the qualitative characteristic of something, not just a submerged unidentified quality or tone. Sense is also different from signification. The latter involves use of a quality as a sign or index of something else, as when the red of a light signifies danger, and the need of bringing a moving locomotive to a stop. The sense of the thing, on the other hand, is an immediate and immanent meaning; it is meaning which is itself felt or directly had. (Dewey 1925: 200)

So, somewhat in line with Dewey, I am saying that our capacity to experience and make meaning - to make sense of things - does indeed require use of some thing, event, or quality as an indication of some past, present, or future experience. "Making sense" is not just having a feeling about a situation, but instead involves marking significant patterns, tendencies, and consequences of some aspect of an experience. Our linguistic signs are not our only resources for sense-making. There are meaningful patterns in spontaneous gesture, music, painting, sculpture, architecture, dance, and ritual practices, and all of these allow us to grasp the meaning of a situation. I see no good reason to deny that these non-linguistic processes are part of human meaningmaking.

What I have just called "non-linguistic processes of meaning making", Dewey sometimes included as part of language, because he uses that term in a very broad way that far exceeds the use of words proper. This expansion of the scope of language is quite explicit by the time Dewey published Logic: The Theory of Inquiry, where "language" includes anything that could stand in a sign relation to something else:

Language is taken in its widest sense, a sense wider than oral and written speech. It includes the latter. But it includes also not only gestures but rites, ceremonies, monuments and the products of industrial and fine arts. A tool or machine, for example, is not simply a simple or complex physical object having its own physical properties and effects, but is also a mode of language. For it says something, to those who understand it, about operations of use and their consequences. (Dewey 1938: 51-52)

This broad use of the term "language" is the second strategy for answering the Linguistic Pragmatist. The first strategy was to posit meaning - and thus meaningful experience - that is significant and normative, even though it is not dependent on language. Meaning in this sense reaches down deep into our ways of inhabiting and making sense of our world. It involves feelings, emotions, images, and qualities. When it gets expressed through language, it may achieve depth and scope of meaning that is not otherwise possible without language. But there is meaning there nonetheless, and sometimes it is a fullness of meaning that cannot be grasped by any linguistic structure.

The second strategy is simply to include all of these meaning-making processes under the category of language processes, broadly construed. This amounts to Dewey's wide and expansive sense of language.

I prefer the first strategy, chiefly because most people think of language as operating with words, and so they have a hard time expanding that term to encompass the full 
range of meaning processes to include non-linguistic elements. Linguistic pragmatists tend to adopt this traditional narrower notion of language, and so showing the existence of meaning that exceeds language might possibly carry some argumentative weight with them.

\section{The Experience of Language}

So far, I have been arguing that our forms of meaning-making are not necessarily or exclusively bound to a capacity for spoken or written language. It might well be a condition of meaning that a thing, quality, or event must be able to stand as a sign of some experience or aspect of an experience, but the range of things that can realize such a sign relation is clearly not limited to language. Consequently, the lingualist idea that philosophy need only focus on matters concerning our uses, via language, of certain concepts or propositions is both false and misleading.

Beyond this argument about the nature of meaning, there is another serious issue that needs to be considered. The linguistic pragmatist argues that we cannot resort to "experience" as a ground for the possibility of language, because we can never step outside language to grasp some essential feature(s) of an alleged experience. Recall Rorty's well-known words with which I introduced the notion of linguistic pragmatism: "But there is no way to think about either the world or our purposes except by using our language. One can use language to criticize and enlarge itself, as one can exercise one's body to develop and strengthen and enlarge it, but one cannot see language-as-a-whole in relation to something else to which it applies, or for which it is a means to an end" (Rorty 1982: xix).

Can you "think" about the world without language? Once again, it depends on what you mean by "think" and what you mean by "language". Can you, without language, have experience that is meaningful, that makes sense to you, that generates inferences, and that leads to further experience? I have argued that you can, and not just on rare occasions (through, say, poetry and art), but much of the time in our lives when we grasp the meaning of what is happening in ways that do not rely on words.

Can you make truth claims (and other speech acts) without language (and the attendant notions of concepts and propositions)? Well, John Austin showed that you most certainly can, even if most of our speech acts do require language. He showed just some of the many ways of making assertions without saying anything, such as the rolling of one's eyes to express disbelief of what another has just claimed, or the shaking of one's head from side to side, or the extending of one's arm with palm upright and facing the interlocutor, in order to indicate refusal of a proposition. These are all meaningful signs, even though none are linguistic.

Linguistic pragmatists tend to endorse Rorty's infamous claim that we cannot depend on any notion of the nature of experience as a way of validating a particular philosophical view, for experience is always linguistically mediated from the get-go. My response to this is to acknowledge Rorty's insight that no account of experience can serve the role of some allegedly ultimate ground of meaning, knowledge, or value. Rorty was right to dismiss objectivist metaphysical projects that pretend to 
ground our philosophies and sciences in some absolute description of the character of experience. Saying that we can experience meaning and think without language doesn't deny Rorty's reasonable claim that all our sense-making is perspectival and that our systems of signs are not windows on absolute reality.

However, Rorty's rejection of foundational metaphysics is perfectly compatible with the idea that philosophy cannot avoid reference to experience, since linguistic activity is itself an experience. We cannot set up language as an autonomous object or system completely independent of some person and group's experience of language. There is no use of language, for any purpose, mundane or philosophical, that does not involve our experience of language. Rorty was probably right that we cannot contrast language-as-a-whole with some non-linguistic experience, but he failed to appreciate that language is a dimension or aspect of experience - one way experience plays out.

Sometimes this claim strikes me as obvious, but at other times it appears to me to be a very subtle point, so let me explore it a bit further. My key point is that language has to be enacted, realized, undergone, and experienced in order to be meaningful and useful. Words, phrases, and sentences do not have meaning in themselves! They have meaning for someone who has developed linguistic capacities and is currently enacting meanings within some language community. Words have meanings for us just because, and insofar as, our hearing or reading of those words within an experiential context activates in our body and brain certain patterns of neural connectivity, plus the release of hormones and other chemical markers within the body that affect our bodily states.

The strongest support I know for this claim comes from recent empirical research from the perspective of what is known as the "simulation theory of meaning" (or Simulation Semantics). The basic idea of Simulation Semantics is that processing language is not an intellectual grasping of fixed and stable conceptual entities, but rather involves a neural simulation that activates the sensory, motor, and affective structures that would actually be activated in the scene being described. Psychologist Benjamin Bergen describes the simulation view as follows:

The idea is that you make meaning by creating experiences for yourself that - if you're successful - reflect the experiences that the speaker, or in this case the writer, intended to describe. Meaning, according to the embodied simulation hypothesis, isn't just abstract mental symbols; it's a creative process, in which people construct virtual experiences embodied simulations - in their mind's eye. (Bergen 2012: 16)

You experience and make meaning by enacting experiences that use the same brain regions for perception, feeling, and action that would be used if you were actually engaged in the situation being described. For example, your concept of a cup is not some transcendent Fregean sense - an abstract quasi-entity grasped by something called the mind. Rather, your concept cup is constructively enacted in a given context in terms of the types of perceptions (visual, tactile, auditory, etc.) you might have with cups, the types of motor programs you run in picking up, holding, moving, and drinking from cups, and the emotional dimensions of various situations in which cups are used in different practical and social settings. 
Simulation Semantics, as a new approach, has so far focused mostly on how we process language, but it can easily be extended to many other forms of (non-linguistic) meaning making. We enact - simulate - not just when we hear or read words, but also when we hear music or view painting, sculpture, architecture, dance, visual scenes, and ritual practices. There is no meaning without an experience of meaning unfolding in time.

For our purposes, the upshot of this is that you cannot have meaning through language without simulated experience (which, note well, is still experience), and the experiences themselves are not linguistic through and through, since they involve the whole relevant physically and culturally embodied situation or context in which you are operating. One important consequence of this is that you cannot use "language" as a contrast term to "experience", in any way that pretends to deny experience a crucial role in our acts of thinking, meaning-making, communicating, problem-solving, and creativity. The mistaken idea that we can replace our experience of something with our language for talking about that experience is a non-starter from the perspective of human cognition. What I am objecting to is the tendency of linguistic pragmatists either to cash out experience in linguistic terms, or else to reject any serious reference to experience as transcending language, through deeply embodied dimensions of meaning making.

The view I have developed here can be summarized as follows: Linguistic Pragmatism takes language in way too narrow a sense that cannot capture the multitude of ways humans make and experience meaning. If, following Dewey, they were to expand their conception of language to include all forms of symbolic interaction and meaning-making (e.g., art, music, dance, gesture, sculpture, ritual), then they need a vastly enriched theory of meaning that cannot be modeled on the views of language they have so far provided. They need to think of meaning, and, in turn, language, in a far richer and deeper way than they can countenance. However, should they attempt such an expanded view of meaning, they will then have to acknowledge that meaning (and language) involve an embodied, enacted, embedded experience of meaning. Therefore, they cannot continue to insist that we should eschew any significant account of experience.

Dewey devoted a large part of his mature career to writing influential books on experience, nature, logic, art, and morality that argue for his view that everything we perceive, think, feel, and do is a matter of experience, and, furthermore, that all of this activity takes place within an experiential context that cannot itself be made entirely explicit through linguistic descriptions. This is not the place to lay out again Dewey's notion of the pervasive qualitative unity of a given situation as the basis for all meaning, relevance, and thought. It must suffice to say that the world we inhabit, and in relation to which we suffer, strive, value, and act - our world as meaningful - is a world of experience, and not just a world of linguistic experience.

One implication of this is that you cannot, as linguistic pragmatists want to do, say that pragmatism begins with our language, because beginning with language is already beginning with an experience of language, in which dimensions of that experience are integral to, but not constituted by, language (i.e., linguistic structures). 
So, when Brandom tells us that linguistic pragmatism begins with language, and when Macarthur and Price tell us that pragmatism is concerned, not with the experience of X, but with our language about X, I cannot agree. Philosophy, I want to protest, ought to emerge from and reconstruct my/our experience. Language is one part of this working, reconstructive practice, but only one part. Language itself is predicated on other non-linguistic practices, norms, and processes of meaning. When you're dancing with your lover, words tend to get in the way of the meaning transpiring between the two of you. Your preferred philosophy will use words, of course, to talk about that experience, but that doesn't turn dancing into talking.

\section{References}

Bergen B., (2012), Louder Than Word: The New Science of How the Mind Makes Meaning, New York: Basic Books.

Brandom R., (2011), Perspectives on Pragmatism: Classical, Recent, and Contemporary, Cambridge, MA: Harvard University Press.

Dewey J., (1925), Experience and Nature, in The Later Works, 1925-1953, Vol.1, ed. by J.A. Boydston, Southern Illinois University Press, Carbondale and Edwardsville, 1981.

- (1938), Logic: The Theory of Inquiry, in The Later Works, 1925-1953, Vol. 12, ed. by J.A. Boydston, Southern Illinois University Press, Carbondale and Edwardsville, 1991.

Johnson M., (2007), The Meaning of the Body: Aesthetics of Human Understanding, Chicago: University of Chicago Press.

Macarthur D. and Price H., (2007), "Pragmatism, Quasi-Realism, and the Global Challenge", in Misak 2007.

Malachowski A., (2010), The New Pragmatism, Durham, UK: Acumen Publishing Ltd.

Misak C., (ed.) (2007), New Pragmatists, Oxford: Oxford University Press.

Rorty R., (1979), Philosophy and the Mirror of Nature, Princeton: Princeton University Press.

- (1982), Consequences of Pragmatism, Minneapolis: University of Minnesota Press. 
Searle J., (1969), Speech Acts, Cambridge: Cambridge University Press.

Talisse R., and Aiken S., (eds.) (2011), The Pragmatist Reader: From Peirce through the Present, Princeton: Princeton University Press. 